\title{
Preface to Innovations in WEEE Recycling
}

\author{
Bernd Friedrich $^{1}$
}

Published online: 30 May 2018

(C) The Minerals, Metals \& Materials Society 2018

The steadily increasing level of technology not only in society but also in the economy is accompanied by a growing number of electronic devices-particularly in the fields of communication, information and entertainment. The high performance and functionality of electronic devices such as mobile phones, computers and televisions require appropriate hardware components and therefore the use of technology metals with the ability of rapid transmission and handling of large amounts of data. Therefore, metals such as copper, tin, gold, silver, tantalum, gallium and indium play an outstanding role in the production of electrical and electronic devices. Since a lot of these devices already reach the end of their life cycles in less than 10 years, significant amounts of Waste Electric and Electronic Equipment (WEEE) are generated every year. According to the Global E-Waste Monitor in 2016, 44.7 Mt of WEEE were generated worldwide, of which only $20 \%$ were recycled. Compared to natural resources, WEEE exhibits a much higher concentration of several technology metals such as copper and precious metals, whereas the content of (critical) trace metals (i.e., In, Ga, Ge, Ta) is located in the range of primary ores. Hence, for those countries without mining activities, WEEE represents a high resource potential for recovering these metals.
Fig. 1 Concentration of $\mathrm{CO}_{2}$, $\mathrm{CO}, \mathrm{CH}_{4}$, and $\mathrm{H}_{2}$ at different temperatures. Reproduced with permission from Diaz et al. [1]
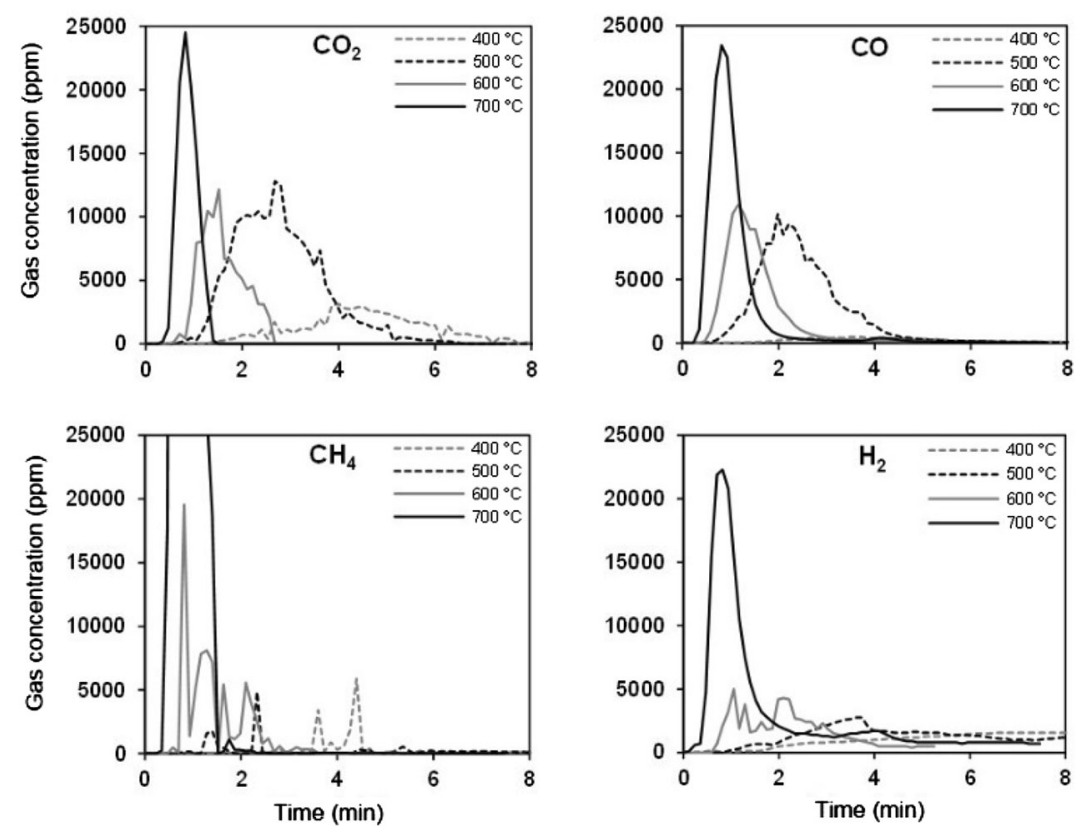

Bernd Friedrich

bfriedrich@ime-aachen.de

1 Department of Process Metallurgy and Metal Recycling, RWTH Aachen University, Intzestraße 3, 52056 Aachen, Germany 
Fig. 2 Process for efficient metal recycling from filter dust. Reproduced with permission from Borowski et al. [2]

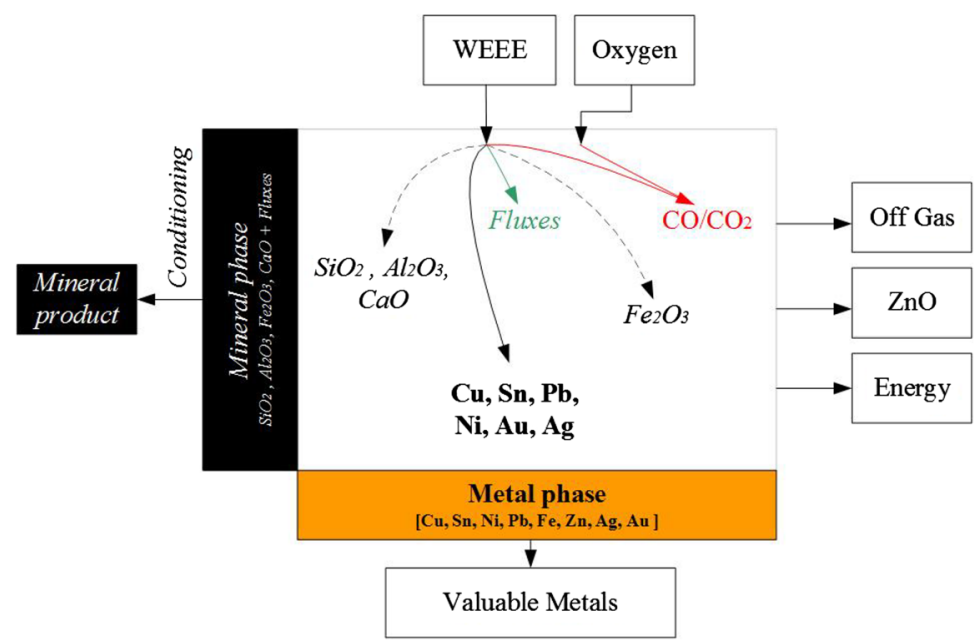

However, in practice the metallurgical extraction of metals from WEEE faces new challenges, ranging from economic issues to environmental concerns.

Besides a wide range of metals, about $70 \mathrm{wt} \%$ of WEEE are accounted for by organics, glass and ceramics, making it a highly complex waste stream. The pyrometallurgical recycling of WEEE has already reached the scale of industrial recycling, since it generally allows high mass throughputs as well as an effective recovery of metals such as copper, tin and precious metals. However, the high organic fraction limits these operations due to the high energy and off gas generation (Fig. 1). Only smelters which operate at a high technical level with state-of-the-art environmentally sound processes can cope with large volumes of this waste stream. Nevertheless, ignoble minor metals are lost in slags and flue dusts so that a holistic recovery cannot be achieved. Furthermore, the obligatory mechanical pre-treatment processes are cost-intensive, causing further metal losses as they are dispersed into different side or waste streams.

To overcome these shortcomings, numerous research projects have been conducted and are still ongoing in order to develop alternative and innovative approaches in WEEE recycling. This special issue presents a number of promising research activities (Fig. 2). The goal is to point out sustainable recycling concepts which enable multiple metals to be recycled by using flexible processes and linking mechanical/physical and metallurgical methods. A balanced overview on different WEEE pre-treatment processes as well as pyro- and hydrometallurgical recovery methods are presented. The research article focuses on both the recovery of noble metals and the economically viable recycling of minor elements.

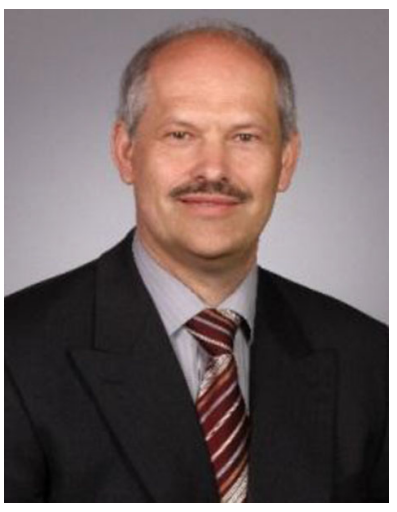

Finally, I would like to acknowledge all authors and reviewers who made this special issue possible. Special thanks are given to my colleagues, acting as handling editors for all of the papers that I have co-authored.

\section{References}

1. Diaz F, Flerus B, Nagraj S, Bokelmann K, Stauber R, Friedrich B (1991) Comparative analysis about degradation mechanisms of printed circuit boards (PCBs) in slow and fast pyrolysis: the influence of heating speed. J Sustain Metall. https://doi.org/10. 1007/s40831-018-0163-7

2. Borowski N, Trentmann A, Brinkmann F, Stürtz M, Friedrich B molten slag bath. J Sustain Metall. https://doi.org/10.1007/s40831018-0159-3 (2018) Metallurgical effects of introducing powdered WEEE to a 